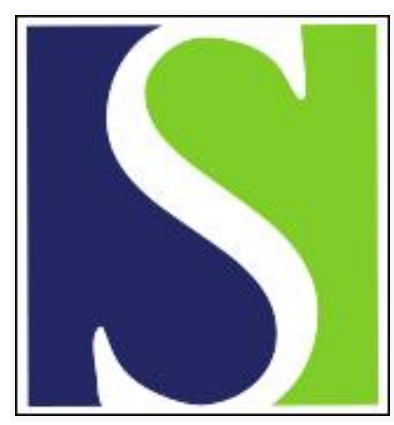

Scand J Work Environ Health 1994;20(3):153-159

https://doi.org/10.5271/sjweh.1414

Issue date: 01 Jun 1994

Work load and musculoskeletal complaints during pregnancy. by Paul JA, van Dijk FJH, Frings-Dresen MHW

Affiliation: Coronel Laboratory and Study Center on Work \& Health, Faculty of Medicine, University of Amsterdam, The Netherlands.

This article in PubMed: www.ncbi.nlm.nih.gov/pubmed/7973486 


\title{
Work load and musculoskeletal complaints during pregnancy
}

\author{
by Jeannette A Paul, PhD, Frank JH van Dijk, PhD, Monique HW Frings-Dresen, PhD'
}

PAUL JA, VAN DIJK FJH, FRINGS-DRESEN MHW. Work load and musculoskeletal complaints during pregnancy. Scand J Work Environ Health 1994;20:153-9.

\begin{abstract}
OBJECTIVEs - Many pregnant women have musculoskeletal complaints, the onset and aggravation of which are thought to be associated with their activity or work postures. The purpose of this paper was to obtain more insight into the influence of pregnancy on the load of the musculoskeletal system at work to provide a better basis for preventing complaints.

METHODS - To this end, literature pertinent to a model called "work load of the musculoskeletal system" was reviewed. The model was developed to describe how work contributes to musculoskeletal complaints.

RESults - It was found that pregnancy causes changes in a worker's characteristics. These changes can lead to changes in the work situation, activity pattern, and postural characteristics and possibly result in a change in work load. In addition, physical changes such as weight gain increase the work load in a given posture. The load-bearing capacity of the musculoskeletal system decreases due to pregnancy.

Conclusions - The changes in load and the decrease in load-bearing capacity singly or simultaneously increase the risk of musculoskeletal complaints. The multifactorial cause of musculoskeletal complaints during pregnancy reveals various possibilities for prevention.
\end{abstract}

KEY TERMS - biomechanics, ergonomics, low-back pain, models, prevention, review, women, work, work posture.

During pregnancy, many women have musculoskeletal complaints. About half of pregnant women have low-back pain at some time during pregnancy ( $1-$ 4 ), the intensity of the back pain increasing as pregnancy advances (5). The personal and financial consequences of the complaints can be considerable. Low-back pain during pregnancy considerably limits the daily activities of $12 \%$ of pregnant women (6), and as many as $9 \%$ (3) to $21 \%$ (7) are given sick leave. Of 710 employed Norwegian women, 17\% were certified as sick during pregnancy because of musculoskeletal diseases (8). Furthermore, complaints during pregnancy are associated with problems after delivery, such as persistent back pain (3, $7,9)$. Due to the traditional focus on back pain during pregnancy, hardly any research has as yet been done on the occurrence of other musculoskeletal complaints, with the exception of muscle soreness (10).

The kind of work and the work posture, for example, heavy physical work, standing with the trunk bent forward, and twisting, have occasionally been shown to influence the onset and aggravation of back

Coronel Laboratory and Study Center on Work \& Health, Faculty of Medicine, University of Amsterdam, The Netherlands.

Reprint requests to: Dr MHW Frings-Dresen, Coronel Laboratory, Faculty of Medicine, University of Amsterdam, Academic Medical Center, Meibergdreef 15, 1105 AZ, Amsterdam, The Netherlands. pain during pregnancy $(1-4,11)$. However, none of the authors reporting these results were able to explain the mechanism of the association.

The extent of the problem indicates the necessity to study the suggested role of work and work posture. Our objective in writing this communication was to obtain more insight into the influence of pregnancy on the work load of the musculoskeletal system. To this end we have reviewed the literature and have given an overview that will improve insight into the mechanisms involved and provide a better basis for preventing complaints. The reviewed literature concerned the model "work load of the musculoskeletal system," according to the following description.

\section{Model for work load of the musculoskeletal system}

We developed the model "work load of the musculoskeletal system" (figure 1 and table 1) by integrating two existing models [ie, the process by which work contributes to musculoskeletal complaints (12) and the way in which a worker's characteristics influences work load, its consequences, and vice versa (13)]. In our model the worker is an active manipulator.

The "work situation" can be manipulated by workers who anticipate their (changed) capacity (eg, by eliminating heavy tasks after illness). A worker's 
characteristics can influence the use of decision latitude and change the "actual work performance." For example, when a worker does not feel physically fit, he or she will try to postpone tiring tasks. The "work posture and exerted force" are determined by factors such as the nature of the tasks, the work methods, the worker's characteristics (eg, body dimensions and their fit with the workplace layout and work technique) (14). The "load of the musculoskeletal system" is determined by external forces that act on the body (gravitational forces due to body segment mass and the reaction to the force exerted by the worker on the environment). External forces tend to rotate

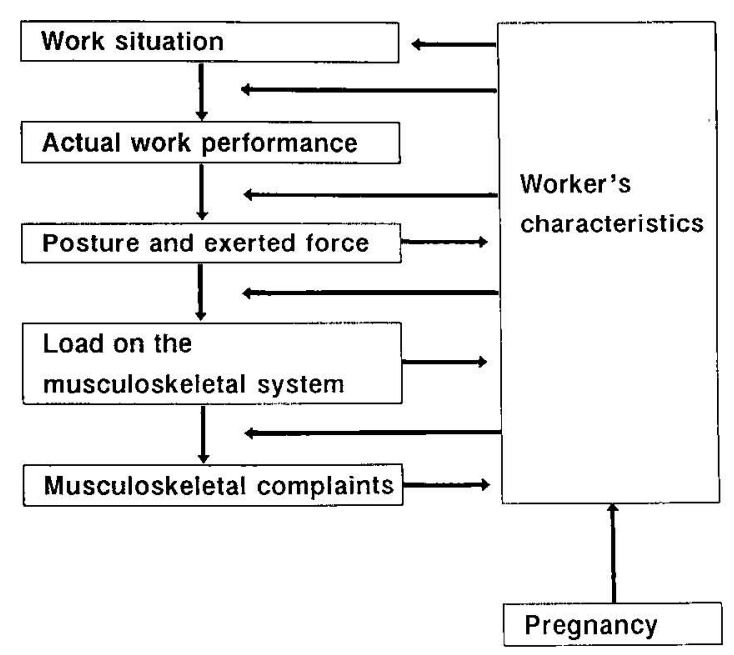

Figure 1. Model "work load of the musculoskeletal system." The way in which pregnancy influences the process through which work contributes to musculoskeletal complaints has been added to the model. the body segment on which they apply around a joint. This rotational motion is called a moment, and its magnitude is influenced both by the position of the body segments in space and by a worker's characteristics, such as body segment dimensions. When movement is present, the inertia of the body segments and handled objects should also be considered (15). To maintain postures and to exert force, muscle force must be generated and ligaments must be loaded. Whether or not "musculoskeletal complaints" develop or become aggravated depends on the balance between the load and the load-bearing capacity of the musculoskeletal system (ie, the capacity of the musculoskeletal system to sustain a certain load with complete recovery of the system afterwards, not causing musculoskeletal complaints in the short term and the long term).

The process by which work contributes to musculoskeletal complaints can also change a worker's characteristics. For example, work posture influences the peak muscle force, the load may lead to muscular fatigue and damage, and the presence of complaints may reduce a worker's motivation.

A step-by-step analysis may yield insight into the mechanisms associated with the onset of musculoskeletal complaints and possibilities for prevention.

\section{Literature reviewed}

A literature search was performed up to December 1992 in Medline. References identified from pertinent literature and Dutch research reports on pregnancy were also incorporated. The indexing terms used concerned the concepts of the model "work load of the musculoskeletal system" in combination with pregnancy. Since literature was scarce, almost all of the located references were studied in detail and

Table 1. Terminology used in the model "work load of the musculoskeletal system."

\begin{tabular}{|c|c|}
\hline Term & Definition \\
\hline Work situation & $\begin{array}{l}\text { The whole of loading work factors and decision latitude for both paid and unpaid } \\
\text { work, such as domestic work }\end{array}$ \\
\hline Loading factors & $\begin{array}{l}\text { Aspects of task contents, work conditions, social relationships and conditions } \\
\text { of employment }\end{array}$ \\
\hline Decision latitude & Potential control of loading factors \\
\hline Actual work performance & $\begin{array}{l}\text { The work situation as it stands (ie, the tasks performed and the work conditions, } \\
\text { social relationships and conditions of employment present) }\end{array}$ \\
\hline Work posture and exerted force & $\begin{array}{l}\text { The body postures during work and forces exerted on the environment by a worker } \\
\text { (eg, pushing and pulling); movements are considered to be a succession of } \\
\text { postures }\end{array}$ \\
\hline Load on the musculoskeletal system & $\begin{array}{l}\text { The net biomechanical load (ie, reaction forces and reactive moments on joints, } \\
\text { their magnitude, direction, frequency and duration determining the total load over } \\
\text { a period); this net load results in loading of muscles, ligaments, and joints }\end{array}$ \\
\hline Musculoskeletal complaints & $\begin{array}{l}\text { Self-reported discomfort, pain, or reduced functionality with regard to the mus- } \\
\text { culoskeletal system }\end{array}$ \\
\hline Worker's characteristics & $\begin{array}{l}\text { The whole of physical, cognitive, and mental characteristics and capacities of a } \\
\text { worker and the motivation to use these capacities; the characteristics, capacities } \\
\text { and motivation are dynamic (le, subject to change); examples are body dimensions, } \\
\text { strength, coping capacity, and expertise; determinants are, for example, pregnan- } \\
\text { cy, age, and gender }\end{array}$ \\
\hline
\end{tabular}


judged as to quality and relevance. Findings relevant to our investigation were combined to yield qualitative results.

\section{Influence of pregnancy on the work load of the musculoskeletal system}

For each step of the process through which work contributes to musculoskeletal complaints, relevant changes in a worker's characteristics due to pregnancy are described, along with their influence on the corresponding step in the process.

\section{Work situation}

Many women develop problems at work because of pregnancy. Tasks and work conditions (eg, heavy physical work, standing, squatting, night work, and irregular workhours) generate problems, particularly during pregnancy (16). In one study the performance of 32 of 46 everyday tasks was judged to be more difficult during pregnancy (17). Difficulties with work may reflect a reduced capacity of pregnant workers. Moreover, pregnancy may affect both a woman's willingness and motivation to perform activities that can harm herself or her unborn child. The acceptance of certain activity patterns during pregnancy differs between cultures. In 51 of 112 societies studied all over the world, full work duties are maintained until childbirth. In the other societies, the work is lightened during pregnancy, the change ranging from $\mathrm{mi}-$ nor alterations to major inactivity (18).

Adaptations of the work situation may be necessary. The main strategies for reducing the work load are to remove loading factors and reduce exposure time. Adaptations can, in several countries, be attained through existing legislation. In The Netherlands, an appeal based on the Working Environment Act $(1980)$ is possible, with refusal to perform dangerous work as a last resort. However, there is no agreement on what should be considered dangerous, and the legislation is often not obligatory. Therefore, adaptations in the work situation can probably be more effectively implemented through informal mutual agreement with the employer (19).

Several studies show adaptations in the work situation during pregnancy. Among 2387 French workers, such adaptations as breaks and shorter workhours $(33 \%)$, more frequent sitting (18\%), and a reduction in the required output $(9 \%)$ have been made. Adaptations were not made either because of refusal by the employer or because they were thought to be unnecessary or impossible by the women themselves (20). In another study, in French firms that conduct activities considered harmful during pregnancy, adaptations granted by employers or physicians were studied among 1168 pregnant women. Changes were made in the workstation $(7.5 \%)$, the number of workhours was reduced by $1 \mathrm{~h}(40 \%)$ or $0.5 \mathrm{~h}(26 \%)$ per day, and sick leaves were given as "preventive rest periods" (many cases) (21). The Quebec Occupational Health and Safety Act provides possibilities for adapting the work situation, and $30 \%$ (ie, close to 15000 women) of the pregnant workers took advantage of this legislation in 1987. Leave with full pay was obtained by $87 \%$ of the women, and only $13 \%$ were able to change their work conditions (22). Among 124 pregnant Dutch women with various occupations, adaptations were attained by about $40 \%$, for instance, improved equipment, work on one floor only (omitting stair climbing), sitting instead of standing, and no stooping and lifting (16).

All these findings show that many pregnant workers can adapt their work situation to fit the circumstances; nevertheless the majority of women with problems are not able to make such changes.

\section{Actual work performance}

Changes in a worker's capacity and motivation due to pregnancy, as has been suggested in the preceding discussion, may influence the use of decision latitude and result in loading factors being manipulated. Of the various aspects of the actual work performance, the time spent at various tasks has been examined in studies on energy requirement during pregnancy. For 162 full-time Scottish housewives (23) and 26 American women with various occupations (24), no change in activity pattern during pregnancy was found, as measured with an activity diary technique. However, for 18 Dutch women without paid employment and with a sedentary life-style, an increase in activity level was found, as measured with detailed physical-activity diaries. On the average they spent $40 \mathrm{~min}$ more in light and moderate household activities in late pregnancy than in early pregnancy (25). Among 40 rural Philippine women occasionally engaged in farming activities, a reduction in physical activity was found during pregnancy (26). The same was the case with 30 rural Gambian women (27). Changes as early as the second gestational month could be assessed by multimoment observation, with the greatest reductions near term (27). It appears that, when the activity level is low, either no change occurs or an increase in activity is seen during pregnancy, while at higher activity levels a reduction in activity is found. However, it is questionable whether the diary technique is sensitive enough to assess the magnitude and kind of changes that occur in activity pattern during pregnancy.

\section{Posture and force exerted on the environment}

Workers' characteristics, such as body dimensions and body weight (distribution), change in a relatively short time during pregnancy. Of 55 body dimensions studied during pregnancy, several depths, widths, and circumferences were shown to change (28). The increase in abdominal depth, on the average $0.38 \mathrm{~cm}$ per week (29), is the most apparent. The average total weight gain during pregnancy is about $12.5 \mathrm{~kg}$, with 
a considerable range from weight loss to weight gain of $23 \mathrm{~kg}$ or more (30). Since the weight increase is mainly located at the anterior side of the trunk, the truncal center of mass is shifted forward (29).

The effects of pregnancy on (muscle) strength have been studied. Upper-extremity strength (ie, hand grip, static arm strength, and dynamic arm strength) did not differ in pregnant and nonpregnant women (31). Another study showed a decline in grip strength from the first to the second trimester, without further changes during the third trimester (28). The maximal push-and-pull force during standing and sitting with the arms at various heights is lower in the third trimester than in early pregnancy (28). The effect of pregnancy on the abdominal muscles was investigated using three kinds of sit-ups (6). Of 164 pregnant women (median pregnancy duration 38 weeks) $13.5 \%$ could perform the most difficult sit-up, while $89 \%$ of 164 nonpregnant women could. Of the pregnant women, $16.6 \%$ could not perform any sit-up, whereas all the nonpregnant women completed one of the three sit-ups as required. The authors attributed the difference in sit-up performance between the two groups to the enlarged uterus, which in pregnancy overstretches the abdominal wall and leads to insufficiency of the abdominal muscles.

The changes in body dimensions and strength may limit or change postures and the exertion of force during pregnancy. The flexion and extension of the hip and trunk decreases systematically throughout pregnancy, and this change has been attributed to spatial obstruction by the protruding abdomen (28). When rising from a chair without the aid of the arms in late pregnancy, the women in one study had a straight back that was hardly inclined to the vertical, while after delivery the women flexed the trunk forward before rising (32). The increased size of the abdomen may cause this postural difference.

The changed mass (distribution) due to pregnancy may increase the risk of loss of equilibrium during activities in which the projection of the wholebody center of mass is displaced forward. Pregnant women in the third trimester have often attributed the increased difficulty with reaching high shelves and cleaning windows to instability and loss of equilibrium (17).

Furthermore, changes in fit may occur with the workplace layout. When working at a desk, 64 of 200 pregnant women complained of difficulties of fit as the main limiting factor in the third trimester (17). The change in fit may cause postural changes. In pregnant secretaries, trunk flexion increased by an average of 10 degrees from the second to the third trimester while they typed in a sitting position (33).

Changes in posture and in exertion of force during pregnancy may interact. The reduction of maximal push-and-pull force (28) may be due to a reduction in muscular strength, as shown by reduced hand-grip strength, but it may also be due to the inability to adopt postures best suited to apply force.
The inability to perform a sit-up in advanced stages of pregnancy (6) may, besides being due to the suggested abdominal muscular insufficiency, also be caused by the increased weight of the trunk that causes the same sit-up to be heavier in the last stages of pregnancy and by the spatial obstruction of the abdomen that makes the sit-up a difficult movement to perform.

\section{Load on the musculoskeletal system}

Changes in a worker's characteristics may increase work load, given a specific posture. Changes in body segment mass and the forces exerted on the environment change the external forces that act on the body. In addition, changes in posture and the truncal center of mass alter the rotational motion (moment). The changes interact (eg, the increase in low-back load caused by an increase in trunk mass is larger during flexion than in an upright position).

Two studies estimated the effects of weight gain in pregnancy on work load $(32,34)$. Reactive forces and moments around the hip joint were estimated by biomechanical modeling. An increase in body weight of $18.5 \%$ was assumed, as well as a posture with straight legs, a horizontally flexed trunk, and arms which hung loose, vertically downward. The increase in load from before pregnancy to 40 weeks of pregnancy was similar to an increase in load when holding $5 \mathrm{~kg}$ in the hands in this posture before pregnancy (34). Others found that, when a pregnant woman rose from a chair with the aid of the arms so that the pregnancy would have no influence on the posture during the rise, the forces in the knee joints and muscles were higher in late pregnancy than after delivery (32). Thus a given posture can be associated with a higher load on the musculoskeletal system because of pregnancy.

\section{Musculoskeletal complaints}

Several findings suggest a reduction of the load-bearing capacity of the musculoskeletal system during pregnancy. Peripheral joint laxity, assessed by hyperextension at the metacarpophalangeal finger joint, was higher during the last four months of pregnancy than after delivery (35). For the neck, shoulder, elbow, and knee, the range of movement in the flexion-extension plane and adduction-abduction plane of joints increased during pregnancy (28). In both studies the effects of pregnancy were attributed to relaxin or to changed steroid metabolism. Relaxin, mainly generated by the corpus luteum, is present throughout pregnancy, reaching the highest level in the first trimester (36). Relaxin remodels collagen (37), which lowers the strength of connective tissue, permits its expansion, and makes it less rigid (38). Laxity of ligaments has been suggested as a cause of separation and movement in fixed joints of the pelvic girdle (38). In the spine, relaxation of the posterior longitudinal ligament would allow bulging of 
the disk and herniation (39). An increased range of joint movement may reduce joint stability, which may be compensated by constant contraction of the muscles around the joint. This phenomenon would lead to muscular fatigue and longer recuperation periods. The laxity of ligaments and the reduction of muscular strength may shift the burden among the elements of the musculoskeletal system.

The reduction in load-bearing capacity and changes in load may contribute to complaints. Half of pregnant women have low-back pain at some time during pregnancy $(1-4)$. From 12 to 36 weeks of pregnancy the cumulative incidence of back pain was $27 \%$ in one study, but the point prevalence remained stable (mean $25 \%$, range $22-28 \%$ ) (4). Muscle soreness due to pregnancy developed in half of the women without previous complaints (69\%) and became aggravated in two-thirds of the women who already had complaints (31\%) (10).

The etiology of low-back pain during pregnancy is poorly understood. Several pathophysiological causes have been suggested, such as laxity of ligamentous structures in the spine and pelvis due to relaxin $(3,39)$, direct pressure on the lumbosacral nerve roots due to the increased dimensions of the uterus or herniated dises (2), muscular fatigue, referred pain, and pull or pressure on structures of the musculoskeletal system. Various causes of back pain seem to exist during pregnancy.

Three kinds of back pain vary in the course of pregnancy. The number of women with low-back pain decreases, the number with high-back pain remains unchanged, and the number with sacroiliac pain increases (4). Furthermore, positions such as lying, sitting, or standing are aggravating factors for back pain in some women, while they relieve the pain in others $(1,2)$.

The various changes that increase the load or reduce the load-bearing capacity may operate singly or simultaneously, and their relative contributions may change during pregnancy $(2,40)$. In early pregnancy, complaints may be mainly due to changes in load-bearing capacity, while later on in pregnancy the load increase from weight gain or postural changes contributes. Three studies (figure 2) $(1,2,41)$ have shown that, at all stages of pregnancy, back pain develops but that a peak exists from the fifth to the seventh month.

However, in other studies this peak did not exist. Among 34 women without a previous history of back pain, 21 women already had back pain before (average) 18 weeks of pregnancy, and only a small number gained or regained pain during the major growth period (40). For the majority of women with sacroiliac joint dysfunction, pain started in the second trimester $(66 \%$ before a pregnancy duration of 26 weeks) (3). Since there is inconsistency with regard to the pattern of onset of back pain during pregnancy, no further insight has been gained into the relative contribution of the changes in load and load-

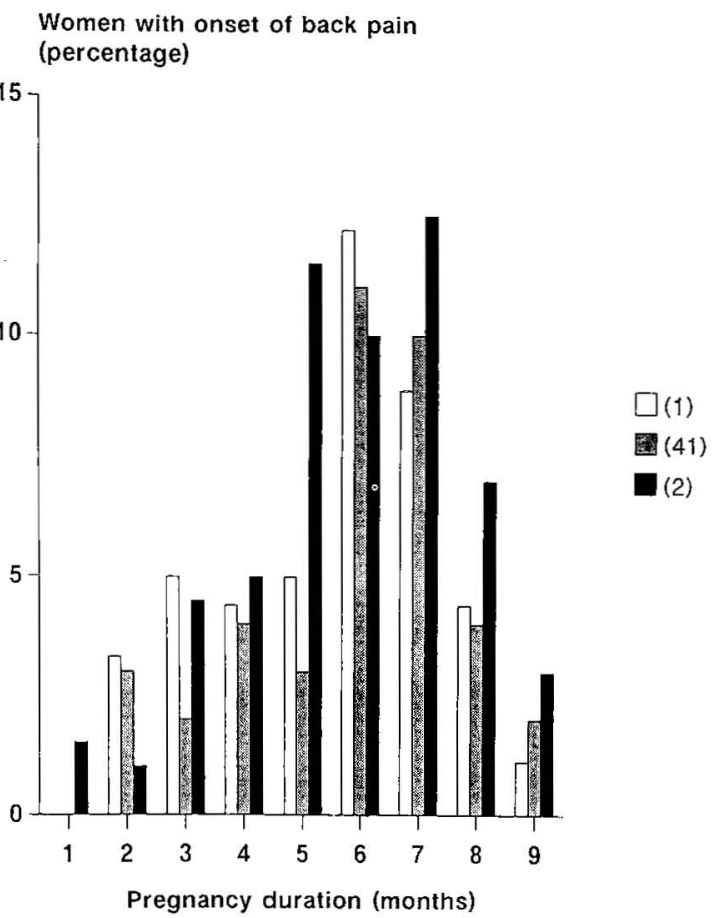

Figure 2. Percentage of women with onset of back pain, per month of pregnancy. The percentages were assessed to enable comparison of the studies, and they were calculated from the number of women with onset of back pain and the population size studied. Population sizes: $N=180$ (1), $N=99$ (41), and $\mathrm{N}=200$ (2).

bearing capacity. In addition, the finding that the intensity of back pain increases with advancing pregnancy (5) does not give more insight.

\section{Concluding remarks}

The idea that during pregnancy back pain is normal, in the sense of being inevitable, is still common. We have negated this idea by discussing various factors and mechanisms that may contribute to the development of complaints and by revealing various possibilities for prevention.

To recapitulate, a worker's characteristics that are changed by pregnancy have a substantial impact on the work load of the musculoskeletal system. The work situations and activity patterns are altered during pregnancy for only a minority of women. Furthermore, postures may be limited and postural characteristics may be changed due to spatial obstruction by the enlarged abdomen, changes of fit with the workplace, and an increased risk of loss of equilibrium. The changes in time spent in various work postures and with certain postural characteristics change the load. Given a specific posture, increased body segment mass and the shift of the truncal center of mass may increase the load, the magnitude of the load increasing according to the posture adopted. The 
load-bearing capacity of the musculoskeletal system is probably reduced during pregnancy due to changes in connective tissue and a reduction in muscular strength. The changes in load and the decrease in load-bearing capacity may increase the risk of musculoskeletal complaints during pregnancy.

To prevent musculoskeletal complaints, various measures are possible, for example, adapting the work situation, changing the use of decision latitude, adapting workplace layout, and improving work posture and work technique. The application of these measures can be stimulated by educating and training workers, employers, and health practitioners and by providing financial incentives and legislation. With regard to some changes that contribute to musculoskeletal complaints during pregnancy, such as weight gain and changes in connective tissue, preventive measures are hardly possible. Prevention has been shown to be effective. Women for whom backcare classes were available in early pregnancy, including ergonomic advice on favorable work postures and lifting techniques, had a lower incidence of back pain than women for whom these classes were not available (42).

However, the literature is limited, even lacking, on some aspects and sometimes inconsistent. Before prevention can be directed more effectively, more insight is needed into the exact nature of various changes and mechanisms occurring during pregnancy and their consequences with respect to musculoskeletal complaints.

\section{Acknowledgments}

The authors thank Professor RH Rozendal, Dr JHAM Verbeek, Ms W van Noppen, and Dr D Kok-Noorman for their critical comments on the manuscript.

\section{References}

1. Mantle MJ, Greenwood RM, Currey HLF. Backache in pregnancy. Rheumatol Rehabil 1977;16:95-101.

2. Fast A, Shapiro D, Ducommun EJ, Friedmann LW, Bouklas T, Floman Y. Low-back pain in pregnancy. Spine $1987 ; 12: 368 \cdots-71$.

3. Berg G, Hammar M, Moller-Nielsen J, Linden U, Thorblad J. Low back pain during pregnancy. Obstet Gynecol 1988;71:71-75.

4. Ostgaard HC, Andersson GBJ, Karlsson K. Prevalence of back pain in pregnancy. Spine 1991;16:549-52.

5. Ostgaard HC, Andersson GBJ. Previous back pain and risk of developing back pain in a future pregnancy. Spine 1991;16:432-6.

6. Fast A, Weiss L, Ducommun EJ, Medina E, Butler JG. Low-back pain in pregnancy; abdominal muscles, situp performance, and back pain. Spine 1990;15:2830.

7. Ostgaard HC, Andersson GBJ. Postpartum low-back pain. Spine 1992;17:53-5.

8. Lundby IH, Stray-Pedersen B, Tellnes G. Diagnoser brukt ved sykmelding av gravide [Diagnoses among pregnant women certified sick]. Tidsskr Nor Laegeforen $1991 ; 23: 2833-6$.
9. Svensson H, Andersson GBJ, Hagstad A, Jansson P. The relationship of low-back pain to pregnancy and gynecologic factors. Spine 1990;15:371-5.

10. Mamelle N, Gerin P, Measson A, Munoz F, Collet P. Assessment of psychological modifications during pregnancy: contribution of Derogatis Symptom checklist (SCL 90-R). J Psychosom Obstet Gynecol 1987;7: 39-50.

11. Cherry N. Physical demands of work and health complaints among women working late in pregnancy. Ergonomics 1987;30:689-701.

12. Hildebrandt VH. Preventie van beroepsgebonden rug problematiek; Perspectieven voor epidemiologisch onderzoek [Prevention of work-related low back problems; perspectives for epidemiological research). Voorburg: Ministry for Social Affairs and Employment, 1988. DGA publication no S35-2-2.

13. Dijk FJH van, Dormolen M van, Kompier MAJ, Meijman TF. Herwaardering model belasting-belastbaarheid [Revaluation of the model workload-capacity] Tijdschr Soc Gezondheidsz 1990;68:3-10.

14. Kilbom A, Persson J. Work technique and its consequences for musculoskeletal disorders. Ergonomics 1987;30:273-9.

15. Chaffin DB, Andersson GBJ. Occupational biomechanics. New York, NY: John Wiley \& Sons, 1984.

16. Maan-Faber ML, Jacobi AM, Buys HY. Faciliteiten voor zwangere werkneemsters [Facilities for pregnant employees]. Den Haag: Ministry for Social Affairs and Employment, 1984. Publication no 840812.

17. Nicholls JA, Grieve DW. Performance of physical tasks in pregnancy. Ergonomics 1992;35:301 - 11.

18. Jimenez MH, Newton N. Activity and work during pregnancy and the postpartum period: a cross-cultural study of 202 societies. Am J Obstet Gynecol 1979;135:171-6.

19. Monster WC, Timmers-de Vin MP. Positierecht; Rechtspositie van zwangere en pas bevallen werkneemsters [Legal position of pregnant employees and employees who recently gave birth]. Alphen aan den Rijn: Samson, 1989.

20. Saurel-Cubizolles MJ, Kaminski M. Pregnant women's working conditions and their changes during pregnancy: a national study in France. Br J Ind Med 1987; $44: 236-43$.

21. Mamelle N, Bertucat I, Munoz. F. Pregnant women at work: rest periods to prevent preterm birth? Paediatr Perinat Epidemiol 1989;3:19 $\mathrm{mm}-28$.

22. Turcotte G. How pregnant workers see their work, its risks and the right to precautionary leave in Quebec. Women Health 1992;18:79-95.

23. Durnin JVGA. Energy requirements of pregnancy. Acta Paediatr Scand 1991;373 suppl:33-42.

24. Blackburn MW, Calloway DH. Energy expenditure and consumption of mature, pregnant and lactating women. J Am Diet Assoc 1976;69:29-37.

25. Raaij JMA van, Schonk CM, Vermaat-Miedema SH, Peek MEM, Hautvast JGAJ. Energy cost of physical activity throughout pregnancy and the first year postpartum in Dutch women with sedentary lifestyles. Am J Clin Nutr 1990;52:234-39.

26. Tuazon MAG, Raaij JMA van, Hautvast JGAJ, Barba CVC. Energy requirements of pregnancy in the Philippines. Lancet 1987;8568:1129-31.

27. Lawrence M, Whitehead RG. Physical activity and total energy expenditure of child-bearing Gambian village women. Eur J Clin Nutr 1988;42:145-60.

28. Moustafa AW. Assessment of some physical characteristics of pregnant women [dissertation]. Birmingham: University of Birmingham, 1986.

29. Hummel P. Changes in posture during pregnancy [dissertation]. Amsterdam: Vrije University, 1987.

30. Hytten FE. Weight gain in pregnancy. In: Hytten F, Chamberlain G, editors. Clinical physiology in obstet- 
rics. Oxford: Blackwell Scientific Publications, 1991: $173-203$.

31. Masten WY, Smith JL. Reaction time and strength in pregnant and nonpregnant employed women. J Occup Med 1988;30:451-6.

32. Ellis MI, Seedhom BB, Wright V. A comparison of knee joint and muscle forces in women 36 weeks pregnant and four weeks after delivery. Eng Med 1985; $14: 95-9$

33. Nicholls JA, Grieve DW. Posture, performance and discomfort in pregnancy. Appl Ergon 1992;23:12832.

34. Snijders CJ, Snijder JGN, Hoedt HTE. Biomechanische modellen in het bestek van rugklachten tijdens de zwangerschap [Biomechanical models in the scope of back complaints during pregnancy]. Tijdschr Soc Gezondheid 1984;62:41-147.

35. Calguneri M, Bird HA, Wright V. Changes in joint laxity occurring during pregnancy. Ann Rheum Dis $1982 ; 41: 126-8$.

36. Bell RJ, Eddie LW, Lester AR, Wood EC, Johnston $\mathrm{PD}$, Niall HD. Relaxin in human pregnancy serum measured with an homologous radioimmunoassay. Obstet Gynecol 1987;69:585-9.
37. Unemori EN, Amento EP. Relaxin modulates synthesis and secretion of procollagenase and collagen by human dermal fibroblasts. J Biol Chem 1990;265: $10681-5$.

38. Maclennan $\mathrm{AH}$. The role of the hormone relaxin in human reproduction and pelvic girdle relaxation. Scand J Rheumatol 1991;88 suppl:7-15.

39. McCarthy SM, Stark DD, Filly RA, Callen PW, Hricak $\mathrm{H}$, Higgins CB. Obstetrical magnetic resonance imaging: maternal anatomy. Radiology 1985;154: $421-5$.

40. Bullock JE, Jull GA, Bullock MI. The relationship of low back pain to postural changes during pregnancy. Aust J Physiother 1987;33:10-7.

41. Nwuga VCB. Pregnancy and back pain among upper class Nigerian women. Aust J Physiother 1982;28:811.

42. Mantle MJ, Holmes J, Currey HLF. Backache in pregnancy II: prophylactic influence of back care classes. Rheumatol Rehabil 1981;20:227-32.

Received for publication: 15 February 1993 